\title{
OVER HERE FROM OVER THERE
}

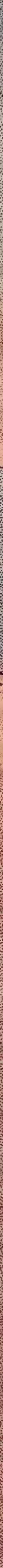

PUBLISHED BY

Delmar Music Co. CHICAGO 


\section{Over Here From Over There}

MIRS. ABBIE F. GA GYYY I
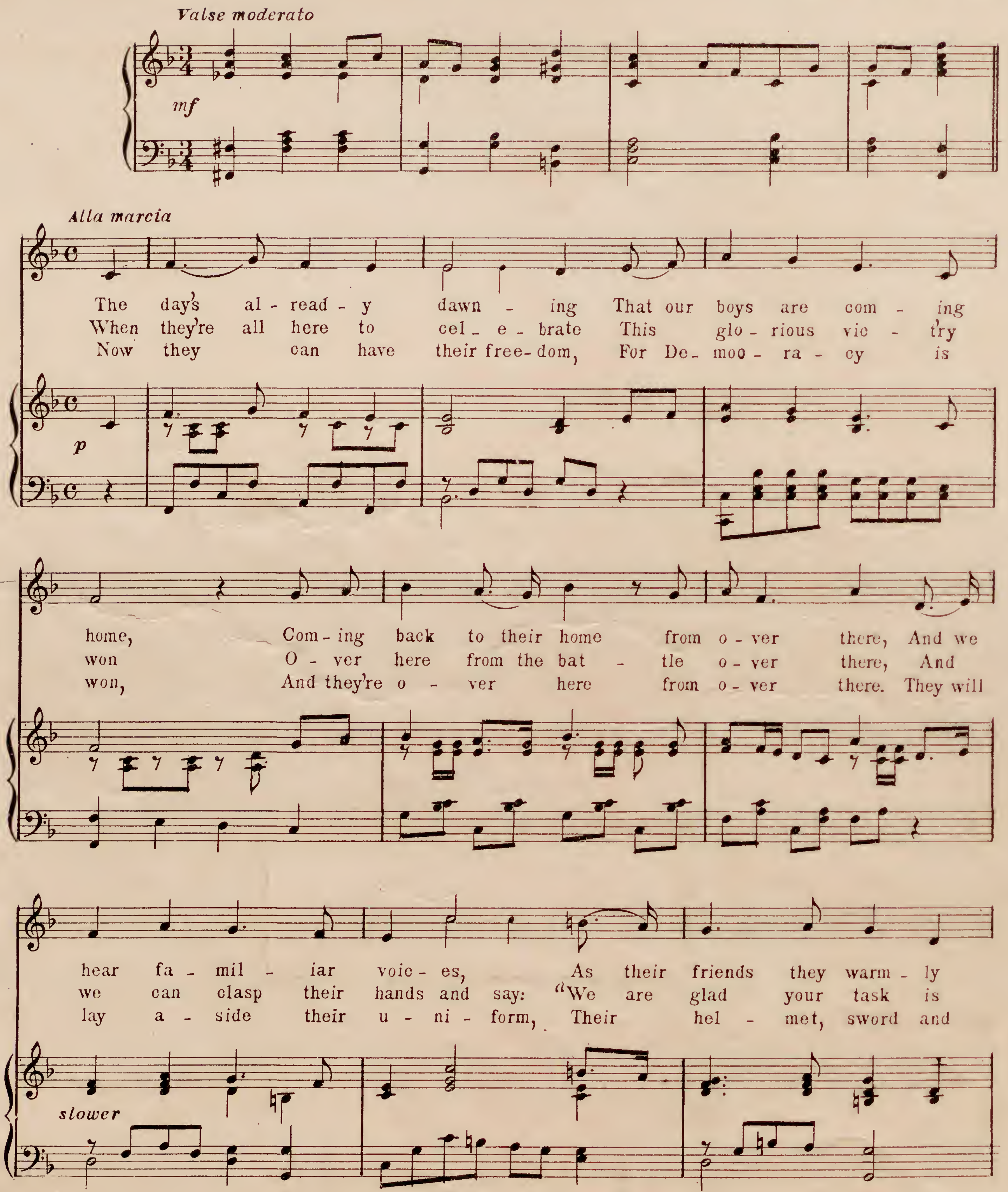


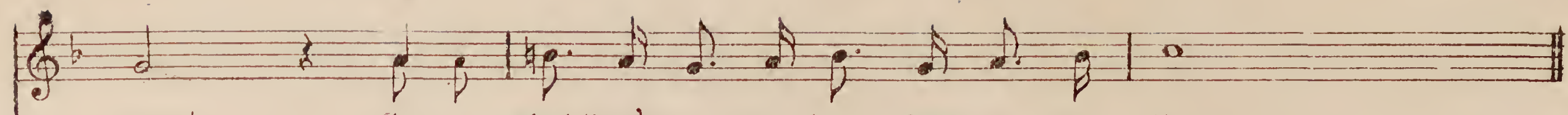
greet, So glad theyle o - ver here from o - ver there, $\begin{array}{ll}\text { done, } & \text { And we have you } 0 \text { - ver here from } 0 \text { - ver there. } \\ \text { gun, } & \text { And be glad they're } 0 \text { - ver here from } 0 \text { - ver there. }\end{array}$

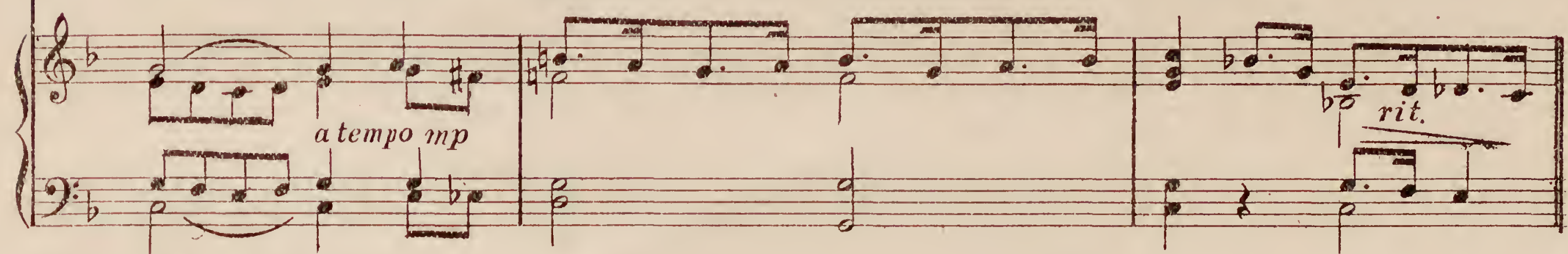
CHORUS: valse moderato

We all are hap - py,

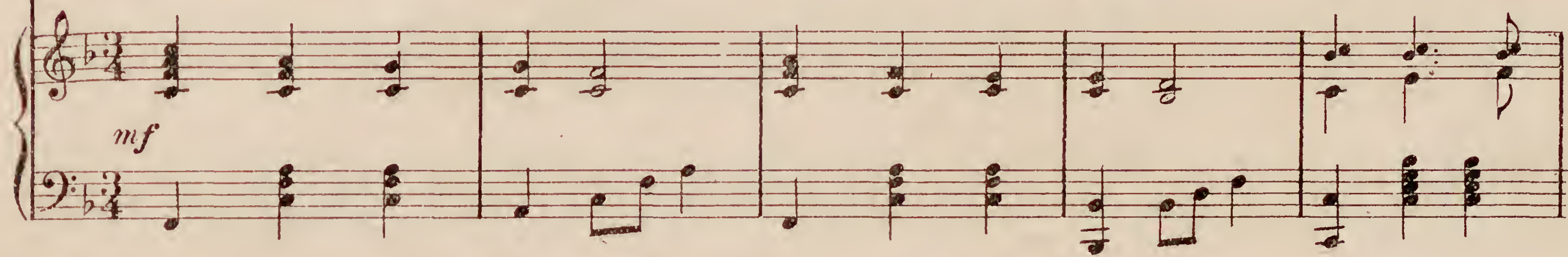

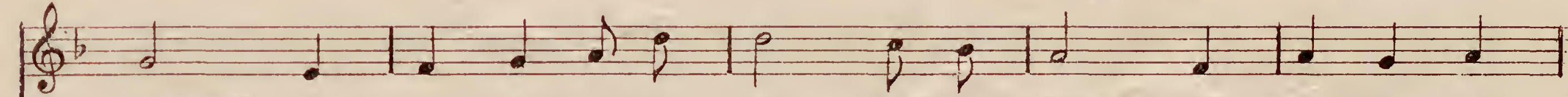

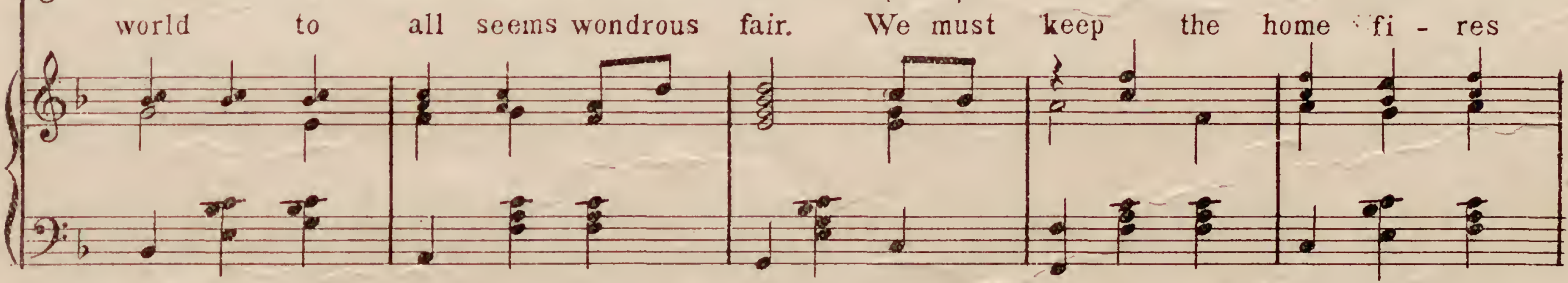

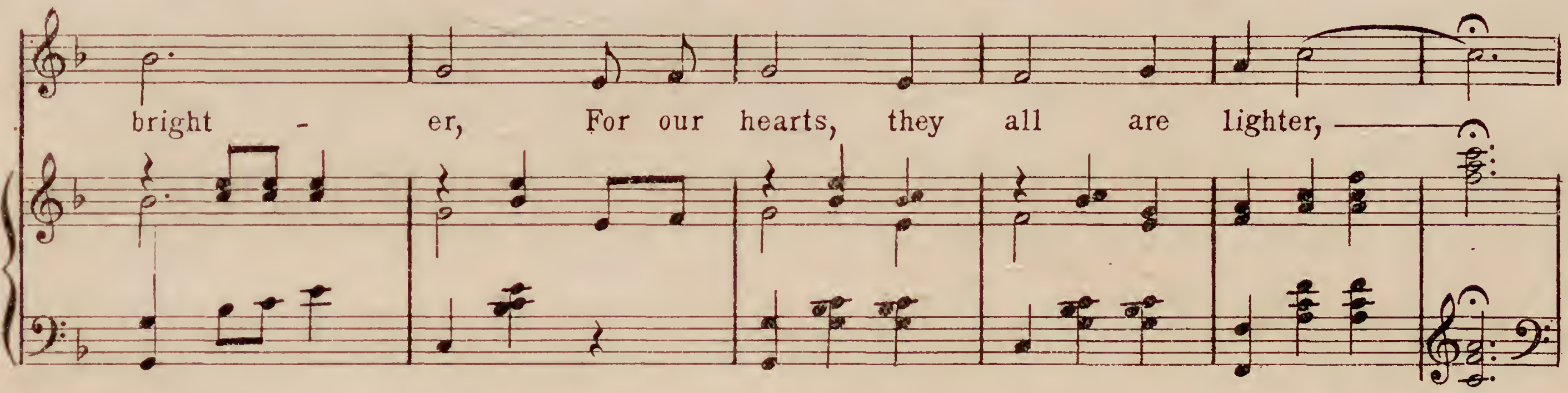

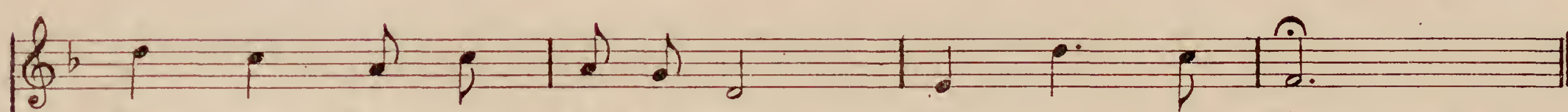

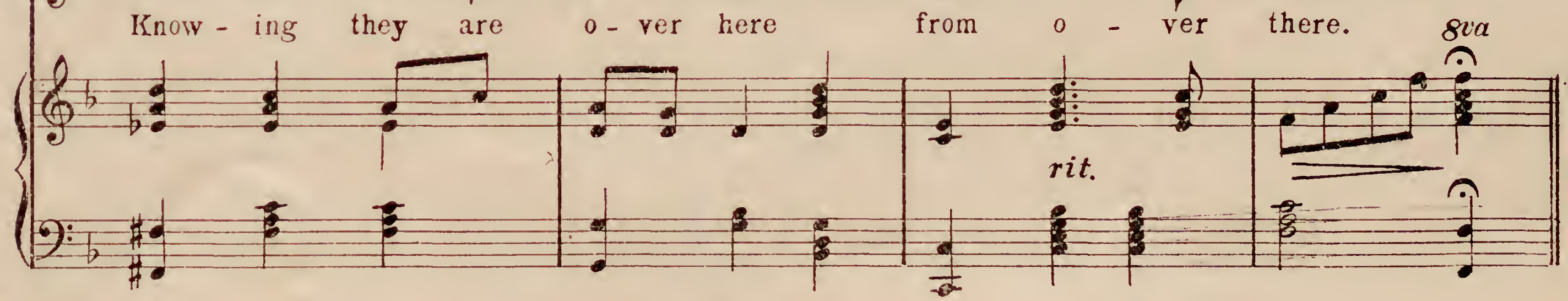
685 
